\title{
A FILOSOFIA POLÍTICA DE MARTÍN DE AZPILCUETA (1492-1586) E A QUESTÃO DA AUTORIDADE CIVIL POPULAR
}

\author{
Marlo do Nascimento ${ }^{1}$ \\ Universidade do Vale do Rio dos Sinos (UNISINOS) \\ (iD) https://orcid.org/0000-0002-6707-7542 \\ E-mail: marlo_kn@hotmail.com
}

\section{RESUMO:}

Neste artigo pretender-se-á estabelecer as bases sobre as quais Martín de Azpilcueta demonstra sua fundamentação da autoridade política no intuito de refletir sobre como este pensador articula sua argumentação no intuito de apresentar o povo como detentor originário, por direito natural, do poder civil. Para que este objetivo possa ser alcançado buscar-se-á apresentar como o autor relaciona e distingue o poder eclesiástico do poder laico ou civil. Em seguida demonstrar-se-á como o pensador espanhol estabelece sua fundamentação da autoridade civil popular ao defender que o poder civil se legitima por ter sua origem em Deus, por ser de ordem natural e ser dado de forma imediata à comunidade dos mortais. A partir disso é possível considerar que a autoridade política laica, conforme o pensamento de Martín de Azpilcueta, tem o povo como seu legítimo depositário e que disso decorre a igualdade original primária de todos os homens na vida pública. Para que se possa realizar o objetivo apresentado neste trabalho estudar-se-á, de maneira específica, a Notabile tertium presente na obra Martín de Azpilcueta chamada Relectio C. Novit de Iudiciis publicada pela primeira vez em Coimbra no ano de 1548.

PALAVRaS-CHAVE: Martín de Azpilcueta; Escolástica tardia; Filosofia política; Poder popular; Direito natural.

\section{THE POLITICAL PHILOSOPHY OF MARTÍN DE AZPILCUETA (1492- 1586) AND THE POPULAR CIVIL AUTHORITY ISSUE}

\begin{abstract}
:
In this article we intend to establish the bases that Martín de Azpilcueta demonstrates his foundation of political authority to reflect on how this thinker articulates his argument to present the people as the original holder of the civil power by natural right. To achieve this objective it will be present how the author relates and distinguishes the ecclesiastical power from secular or civil power. So, it will be shown how the Spanish thinker establishes his foundation of popular civil authority by claiming that civil power legitimizes itself by having its origin in God because it is your natural order and it is given immediately to the community of mortals. According to the thought of Martín de Azpilcueta, it is possible to consider that the secular political authority has the people as its legitimate depository and results in the original equality of all men in public life. In order to accomplish the objective presented in this paper, we will specifically study Notabile tertium present in the work Martín de Azpilcueta called Relectio C. Novit de Iudiciis first published in Coimbra in the year 1548.
\end{abstract}

KEYWORDS: Martín de Azpilcueta; Late scholasticism; Political philosophy; Popular power, Natural law.

\footnotetext{
${ }^{1}$ Doutorando em Filosofia na Universidade do Vale do Rio dos Sinos (UNISINOS), São Leopoldo - RS, Brasil. Bolsista CAPES/PROSUC.
}

NASCIMENTO, Marlo do. A filosofia política de Martín de Azpilcueta (1492-1586) e a questão da autoridade civil popular. Griot : Revista de Filosofia, Amargosa - BA, v.19, n.1, p.65-75, fevereiro, 2019. 


\section{Introdução}

A filosofia política medieval foi fortemente marcada, como já sabemos, por questões que envolvem, principalmente, discussões em torno da relação Igreja e Estado e a respeito da legitimidade dos poderes, a saber, o civil (laico) e o eclesiástico. Essa dualidade dos poderes fez emergir doutrinas bastante radicais e controversas sobre o problema político-jurídico referente a origem do poder laico e a temática do poder supremo, da ideia de uma monarquia universal disputada, historicamente, entre o sumo pontífice romano e o imperador, rei ou príncipe.

Diante disso é possível encontrar duas posições muito claras no âmbito da filosofia política medieval e que Martín de Azpilcueta² leva em consideração para desenvolver o seu pensamento político. Uma conhecida como hierocrática ou teocrática e outra chamada de imperialista. A primeira, busca defender a "tese segundo a qual o Papa, na condição de vigário de Cristo e de sucessor e herdeiro de São Pedro, é o monarca do mundo de iure et facto (direito e fato) entre os cristãos e apenas de iure sobre os infiéis (STREFLING, 2016, p. 25). Num sentido amplo os teóricos da doutrina hierocrática defendem que o papa é detentor supremo do poder espiritual e temporal. Por outro lado, os imperialistas (doutrina que tem sua origem nos cesaropapistas ${ }^{3}$ ) de maneira geral buscam defender a ideia de que o imperador ou rei é possuidor do poder supremo diante de seu povo. Desta maneira os imperialistas alegavam que o poder imperial era dado de maneira imediata e direta por Deus ao imperador e, por isso, ele era possuidor do poder supremo temporal. Estas duas posições antagônicas em disputa, de certa forma, perpassam por boa parte da história da filosofia política medieval. Martín de Azpilcueta em sua obra Relectio $C$.

\footnotetext{
2 Martín de Azpilcueta y Jaureguízar, também conhecido como Dr. Navarro, nascido em Barásoain 13 de dezembro de 1492, de família nobre, começa seus estudos na Universidade de Alcalá em 1509 (sobre os seus estudos em Alcalá ver em: GAZTAMBIDE, José Goñi. Los estudios de Azpilcueta en la Universidad de Alcalá. Príncipe de Viana, n. 245, 2008, p. 905-912), posteriormente, continua sua formação em Universidade de Toulouse, na França, onde se doutora e inicia sua vida de docente. Em grande parte de sua vida teve como ofício principal o magistério, ensinou em várias universidades como Toulouse (1518-1521), Salamanca (1524-1538) e Coimbra (1538-1554) e também foi consultor de reis e papas. Veio a falecer em 21 de junho de 1586 na cidade de Roma. Mais sobre sua biografia pode ser encontrado em: ARIGITA Y LASA, Mariano. El Doctor Navarro don Martín de Azpilcueta y sus obras. Estudio histórico-crítico. Pamplona: 1895; OLÓRIZ, Hermilio de. Nueva biografía del Doctor Navarro, Martín de Azpilcueta y enumeración de sus obras. Pamplona: N. Aramburu, 1916; LÓPEZ ORTIZ, J. Un canonista español del siglo XVI, el Doctor Navarro, don Martín de Azpilcueta. La ciudad de Dios, v. 153, 1941, p. 271-301; TEJERO, Eloy. Los escritos sobre el Doctor Navarro. El el IV centenario de la muerte de Martín de Azpilcueta. Gobierno de Navarra, Pamplona: EUNSA, 1988, p. 21-44; TAPIA, Ramón Martínez. Filosofía política y derecho en el pensamiento español del s. XVI: el canonista Martín de Azpilcueta. Granada: Colegio Notarial de Granada, 1997, p. 23-83; MUÑOZ DE JUANA, Rodrigo. Moral y economía en la obra de Martín de Azpilcueta. Pamplona: EUNSA, 1998, p. 91-102; TEJERO, Eloy e AYERRA, Carlos. La vida del insigne Doctor navarro, hijo de la Real Casa de Roncesvalles: texto manuscrito de Martín Burges y Elizondo. Navarra: Navarra Gráfica Ediciones, 1999.

3 Os Cesaropapistas defendem uma "Teoria de governo segundo a qual os poderes régios e sacerdotais combinamse para ser exercidos por um único governante leigo. A idéia promanou do conceito do imperador romano clássico como chefe da Igreja e do Estado, uma vez que era cultuado como uma divindade. $O$ primeiro imperador cristão, Constantino (306-37), tentou controlar a Igreja promulgando os princípios religiosos a serem observados por seus súditos como dogmas, e nomeando e demitindo pessoalmente os dignitários eclesiásticos. Apesar das promulgações do Concílio de Calcedônia (451), essa política foi mantida pelos imperadores Zenão (474-91) e Justiniano. Embora na Idade Média a autoridade papal fosse largamente aceita no Ocidente, os imperadores bizantinos continuaram exercendo o papel dual como chefe do Estado e da Igreja, e isso, em parte, foi responsável pela ruptura com a Igreja romana" (LYON, 1991, p. 87).
}

NASCIMENTO, Marlo do. A filosofia política de Martín de Azpilcueta (1492-1586) e a questão da autoridade civil popular. Griot : Revista de Filosofia, Amargosa - BA, v.19, n.1, p.65-75, fevereiro, 2019. 
Novit de Iudiciis ${ }^{4}$ busca ponderar estes dois polos de discussão no intuito de apresentar sua filosofia política.

Dentro do que fora dito, este trabalho visa de maneira geral apresentar as bases da filosofia política de Azpilcueta na intenção de tratar mais especificamente, como o pensador espanhol elabora sua fundamentação da autoridade política. E com isso, levar a discutir como Martín de Azpilcueta articula sua argumentação com a finalidade de provar que a autoridade política laica tem no povo o seu legítimo depositário e que disso decorre a igualdade original primária de todos os homens na vida pública.

Para que este objetivo possa ser alcançado buscaremos nos deter, de maneira específica, neste artigo, na Notabile tertium, presente na obra do autor chamada Relectio C. Novit de Iudiciis. Primeiramente, será apresenta essa obra, de maneira geral, para na sequência expor a estruturação da obra na terceira parte desta (Notabile tertium). Em seguida, será desenvolvida a discussão sobre a compreensão do autor sobre os dois tipos de poderes (laico e eclesiástico). Por fim, demonstrar como Martín de Azpilcueta argumenta em favor da ideia de que a autoridade civil é, originariamente, popular, para então discutir sobre as consequências desta sua defesa em meados do século XVI.

\section{Sobre a Relectio in Cap. Novit de Iudiciis ${ }^{5}$}

Esta obra de Martín de Azpilcueta foi editada no ano de 1548, após ter sido pronunciada, no dia 29 de junho do mesmo ano, na Catedral de Coimbra. Esta Relectio tem como fonte inspiradora a decretal Novit Ille ${ }^{6}$ de Inocêncio III, cujo papado se deu entre os anos de 1198-1216. Esta Novit Ille (1204) do papa Inocêncio III é dirigida ao episcopado francês para tratar do conflito existente entre Felipe Augusto (1165-1223), rei dos Francos de 1180 até sua morte, e João Sem Terra (1166-1216) que foi rei da Inglaterra de 1199 até sua morte. O problema entre os dois reis é resultado de uma quebra do juramento de paz realizado entre eles e esta decretal do sumo pontífice busca de certa forma intervir no conflito de ordem temporal justificando razões de pecado. Desta forma, a Novit Ille de Inocêncio III acabou sendo matéria para muitos debates no campo jurídico-filosófico sobre a questão do poder do pontífice romano em assuntos de cunho temporal e assim acirrando a discussão sobre a relação Igreja e Estado.

O Dr. Navarro redige sua Relectio em seis Notabile (Anotações). Na primeira, de maneira breve, trata da onisciência divina. Na segunda, traz para discussão o problema do conhecimento futuro, que resulta na condena aos livros de cavalaria e a

\footnotetext{
4 Ao falar desta obra, Pedro Calafate, nos diz que: “É, de facto, inegável que essa obra do Doutor Navarro é um monumento integrante da doutrina ibérica, emanada de Salamanca, Alcalá, Valladolid, Coimbra e Évora, sobre a origem, natureza e finalidade do poder laico e do poder eclesiástico, e sobre a relação entre o papado e o império, amplamente desenvolvida nas lições de Francisco de Vitoria e Domingo de Soto em Salamanca e posteriormente projetadas por Francisco Suárez na tradição política da modernidade católica" (CALAFATE, 2017, p. 204).

5 Neste artigo usaremos a tradução portuguesa desta obra realizada por António Guimarães Pinto, publicada em: CALAfATE, Pedro. A Escola Ibérica da Paz nas Universidades de Coimbra e Évora (Séculos XVI e XVII) (vol. II). Coimbra: Edições Almedina, 2015, p. 23-181.

${ }^{6}$ Que pode ser encontrada na tradução portuguesa de António Rocha Martins, in: CALAFATE, Pedro. A Escola Ibérica da Paz nas Universidades de Coimbra e Évora (Séculos XVI e XVII) (vol. II). Coimbra: Edições Almedina, p. 183-189, 2015.
}

NASCIMENTO, Marlo do. A filosofia política de Martín de Azpilcueta (1492-1586) e a questão da autoridade civil popular. Griot : Revista de Filosofia, Amargosa - BA, v.19, n.1, p.65-75, fevereiro, 2019. 
reprovação à prática da astrologia. Na Notabile terceira, foco central deste trabalho, tem destaque sua filosofia política de maneira mais estrita, ao tratar de temas como a natureza e origem do poder civil e eclesiástico, bem como a relação entre estes dois poderes. Na quarta e quinta ele põe em evidência o tema da correção fraterna tendo como inspiração central, para tratar do tema, a Novit Ille de Inocêncio III. Na sexta e última Anotação Azpilcueta estabelece a amplitude e jurisdição do poder eclesiástico e por fim dedica-se a apresentar alguns corolários visando concluir os temas expostos na Relectio, além de destacar alguns pareceres que resultam da relação entre moral e economia, a saber, questões como: contrato de compra e venda, usura, preço justo e restituição, temas estes muito debatidos dentre os pensadores da escolástica tardia.

Tendo em vista que a filosofia política de Azpilcueta se encontra de maneira mais direta e objetiva na terceira Notabile é que pretenderemos apresenta-la mais pormenorizadamente. Inicialmente, é importante evidenciar que esta Anotação é estruturada muito de acordo com o método escolástico de tratar os temas em debate. A saber: primeiramente, é apresentada a tese ou tema, logo após seguem as exposições de doutrinas que se opõem entre si tendo como referência o tema inicial. $\mathrm{Na}$ sequência tem-se a doutrina própria do autor e as críticas aos argumentos contrários, para só assim finalizar com um conjunto de corolários derivados de sua doutrina.

Esta terceira Notabile tem como primeiro motor da discussão, a seguinte tese: “o império não se encontra em poder do pontífice romano" (AZPILCUETA, 2015, p. 61). A partir dessa afirmação podemos dividir essa Anotação em quatro quartes. Na primeira parte Azpilcueta apresenta os argumentos usados para defender a doutrina do poder direto do sumo pontífice, doutrina esta que advoga em favor da afirmativa de que a existência do poder temporal se encontra nas mãos do papa. Para isso o nosso autor faz questão de fundamentar os argumentos de cunho hierocrático em quatro grupos. Primeiro grupo tem os argumentos provenientes da escola do Direito Canônico $^{7}$, o segundo do Direito Civil ${ }^{8}$, o terceiro do Direito Divino ${ }^{9}$ e o quarto do Direito natural ${ }^{10}$ (de razão natural).

Na segunda parte dessa Anotação tem-se o parecer contrário ao anterior que visa a apresentação de argumentos que buscam defender a tese da distinção e separação entre o poder civil e o eclesiástico. Para isso, Azpilcueta aplica a mesma estruturação argumentativa da defesa anterior. Apresentando, então, a fundamentação dessa tese através uso dos raciocínios originários do Direito Canônico ${ }^{11}$, do Direito Civil ${ }^{12}$, do Direito Divino ${ }^{13}$ e do Direito Natural ${ }^{14}$.

Na terceira parte é possível encontrar o parecer de Azpilcueta, de caráter sucinto e direto, sobre a tese da autonomia e distinção do poder laico e do eclesiástico. Também nesta parte o autor abre espaço para defender a sua teoria do

\footnotetext{
${ }^{7}$ Destacando as posições dos papas Inocêncio III, Nicolau, Zacarias, Inocêncio IV.

${ }^{8}$ Destacando os imperadores que reconheceram que o poder do império é recebido através do papa.

${ }^{9}$ Baseando-se este parecer nas sagradas escrituras.

10 É usado o pensamento de Aristóteles para defesa de uma razão natural para essa posição.

11 Cita Inocêncio III, Baldo, Agostinho, Gregório Nazianzeno, Cipriano, papa Nicolau, papa Gelásio, Ambrósio, papas Honório III e Alexandre III.

12 Cita o imperador César, Alberico, Felipe (cognominado o Belo), todos os reis da Hispânia.

13 Basicamente ancorado nas sagradas escrituras.

${ }^{14} \mathrm{Na}$ defesa deste parecer tem-se: Antonio Roselli, Rómulo (primeiro rei dos romanos), Numa Pompílio e Moisés.
} 
poder indireto do sumo pontífice sobre questões de ordem temporal. Assim, o autor segue com as críticas aos erros que, segundo ele, podem ser encontrados em ambas as posições, anteriormente, postas em confronto. E desta maneira, posiciona-se como contrário aos que defendem a tese de que o papa é portador do poder supremo, no entanto, ele apoia, através de sua argumentação, que o papa pode, em determinadas condições, ser o possuidor legítimo dos dois poderes.

Na quarta e última parte se encontra o ponto mais relevante dessa Anotação, tendo em vista o objetivo deste trabalho, que é onde o autor elabora de maneira sistemática a questão da distinção entre os poderes. Destacando qual é a origem, natureza e finalidade do poder laico e eclesiástico. A partir deste momento é possível encontrar, de maneira clara e direta, a sua defesa do poder laico de origem popular dado por direito natural. Na sequência segue com uma análise minuciosa dos argumentos presente na doutrina hierocrática expostos na primeira parte desta Notabile, realizando dessa forma sua crítica às justificativas dessa corrente, destacando ainda sua fundamentação da teoria do poder indireto do sumo pontífice. Finaliza esta parte com um conjunto de corolários.

\section{Sobre os Poderes}

Como já mencionado anteriormente, Azpilcueta apresenta nas duas primeiras partes da Notabile Tertium raciocínios de duas concorrentes que divergem sobre a questão do poder supremo do papa. Após apresentar os argumentos de ambas as doutrinas é possível encontrar seu próprio parecer sobre a questão ao dizer:

[...] creio, em primeiro lugar que não se deve perfilhar o ponto de vista dos que dizem que o poder supremo laico de todos os reis está nas mãos do papa, não apenas em hábito, mas também em ato; nem tão-pouco, o do comum dos nossos, que dizem que o poder supremo laico se encontra pelo menos em hábito nas mãos do papa; nem o de outros que afirmam que o poder supremo laico de tal maneira se opõe ao poder supremo eclesiástico que ambos não podem simultaneamente coincidir numa única e mesma pessoa; nem o de outros, que asseveram que o poder eclesiástico de modo algum se estende às coisas temporais; nem o daqueles que defendem que os dois referidos e mesmos poderes supremos, a saber, o eclesiástico e o laico, não podem coincidir na mesma pessoa (AZPILCUETA, 2015, p. 78).

De certa forma, nesta passagem, o pensamento político de Azpilcueta se coloca de maneira direta e clara. É possível extrair dela várias colocações que são centrais para compreender o que autor vai tratar de defender na sequência. Assim sendo o Dr. Navarro, buscar rejeitar, criticamente, as quatro posições seguintes, que podemos apresentar assim:

1) os argumentos dos que defendem que papa é possuidor do poder supremo laico de todos os reis em hábito e em ato;

2) os que afirmam que o poder supremo laico se encontra pelo menos em hábito nas mãos do sumo pontífice;

3) a ideia dos que defendem que o poder laico e o eclesiástico opõem-se entre si e que ambos os poderes não podem coexistir em uma mesma pessoa;

NASCIMENTO, Marlo do. A filosofia política de Martín de Azpilcueta (1492-1586) e a questão da autoridade civil popular. Griot : Revista de Filosofia, Amargosa - BA, v.19, n.1, p.65-75, fevereiro, 2019. 
4) dos que defendem que o poder eclesiástico de nenhuma maneira pode se estender sobre matérias de cunho temporal.

Para melhor adentrar no posicionamento de Azpilcueta diante destas questões é importante destacar o que ele entende com a ideia de poder em hábito e poder em ato. Como bem explica Pedro Calafate (2017, p. 209), Azpilcueta faz uso destes conceitos, de cunho aristotélico-tomista, de hábito e ato remontando as Categorias de Aristóteles (cat., 15, 15b, 16-25) e a Suma Teológica (I-II, q. 49, a.1-3) de Tomás de Aquino. Nas categorias, o pensador grego, apresenta o conceito de hábito como um termo genérico, que destaca a disposição de algo em ordem a um fim e que dificilmente possa ser mudado. Este conceito mais tarde é revisitado por Tomás de Aquino, entendendo que o hábito, primeiramente e por si, tem uma relação com a natureza do ser. Desta forma o hábito que por residir na natureza do ser tende ao ato, conclui-se, disso que o hábito indica uma ordem de agir. Deriva desta compreensão o entendimento de Azpilcueta de "que inicialmente o povo não transferiu o poder aos reis, tendo-o apenas concedido. Ao conceder e ao não transferir, conservou o poder em hábito, podendo recuperá-lo em ato em situações de necessidade extrema" (CALAFATE, 2017, p. 209).

Ao seguir essa linha de raciocínio o autor da Relectio, se coloca diante da primeira e segunda posição, defendendo a tese de que o sumo pontífice não possui o poder supremo laico de todos os reis em hábito e nem em ato devido ao fato de que este poder é, inicialmente, do povo. Dessa maneira Azpilcueta rejeita as duas primeiras posições expondo a seguinte colocação: "o romano pontífice, na medida em que é apenas pontífice romano e supremo vigário de Cristo, mas desprovido de todos os privilégios e tesouros humanos, não possui nenhum poder laico, nem supremo, nem médio, nem ínfimo, nem em hábito nem em ato" (AZPILCUETA, 2015, p. 9596).

A terceira e quarta das posições são rejeitadas pelo autor ao destacar que ambos os poderes não são opostos entre si, e sim, distintos ao dizer que "o poder eclesiástico instituído de um modo novo por Cristo [...] e que é uma espécie de poder diferente do laico e muito mais nobre que ele, $[\ldots]$ e que este poder de modo direto só abrange as coisas sobrenaturais" (AZPILCUETA, 2015, p. 95-96). Destacando assim, que o papa só possui o poder direto sobre coisas sobrenaturais distinguindo as das naturais. Quanto à possibilidade de ambas as espadas coexistirem numa mesma pessoa, nos diz o autor que:

[...] na medida em que os sumos pontífices, possuem o supremo poder eclesiástico, e na medida em que são reis supremos da cidade de Roma e muitas outras terras, por doação de Constantino, Carlos Magno e outros imperadores, que possuem nas mesmas terras o poder supremo laico (AZPILCUETA, 2015, p. 95-96).

Desta forma, defende de maneira direta a possibilidade de o papa ser o senhor dos dois poderes, o eclesiástico, por ser sumo pontífice, e o laico. Porém, o poder laico que tem ou que possa vir a ter não deriva de seu poder eclesiástico e sim por doação de imperadores ou reis. Fortalecendo mais uma vez a ideia de defender uma distinção clara entre os poderes. Outra posição que Azpilcueta buscar rejeitar é a dos defendem que o poder eclesiástico de modo algum possui sua extensão sobre o universo do

NASCIMENTO, Marlo do. A filosofia política de Martín de Azpilcueta (1492-1586) e a questão da autoridade civil popular. Griot : Revista de Filosofia, Amargosa - BA, v.19, n.1, p.65-75, fevereiro, 2019. 
temporal. Neste caso, se posicionará como um defensor da teoria do poder indireto do papa. Ao ressaltar que o poder eclesiástico possui poder direto sobre "as coisas sobrenaturais, e indiretamente as naturais só na medida em que são necessárias para a consecução do fim sobrenatural" (AZPILCUETA, 2015, p. 79). A partir de então, o Dr. Navarro introduz sua doutrina do poder indireto destacando que não são dois os poderes que o romano pontífice ostenta, e sim, apenas o poder espiritual, sobrenatural, não recebido em virtude de algum direito humano. É um direito concedido de Cristo para Pedro e seus sucessores que tem como objetivo direto somente as coisas espirituais e que se estende também como objeto indireto as coisas naturais, não por sua natureza temporal senão por sua relação direta com o fim sobrenatural (CASTAÑEDA, 1942, p. 79). Além desta passagem anterior, na qual Azpilcueta mostra o seu reconhecimento do poder indireto do poder eclesiástico sobre assuntos temporais temos esta outra, que ele nos ajuda a entender quando é que este tipo de poder pode ser usado em assuntos temporais, a saber:

[...] o poder eclesiástico principal e diretamente só diz respeito às coisas sobrenaturais e espirituais, mas ao temporal não, a não ser por consequência e acessoriamente. $\mathrm{E}$ assim este poder estende-se às coisas temporais sempre e só quando o interesse do Evangelho e da conservação das outras coisas sobrenaturais e espirituais, ou obtê-las ou não embaraçálas, tal exigem (AZPILCUETA, 2015, p. 100).

Desta maneira o pensador espanhol se posiciona quanto a extensão desse poder indireto da Igreja, revelando ainda sua discordância diante da posição de Marsílio de Pádua, em seu tratado Defensor Pacis ${ }^{15}$, que segundo o Azpilcueta (2015, p. 102), erra, pois, arranca à Igreja toda a coerção e jurisdição.

Além disso, no intuito de melhor definir e aclarar a distinção entre o poder eclesiástico e o laico é que o autor da Relectio vai buscar na teoria das causas de Aristóteles uma ferramenta. Esta que é usada por Azpilcueta (2015, p. 96) para demonstrar que os dois poderes diferem um do outro na causa material, formal e final e, de certa maneira, na eficiente. Desta forma a distinção no que se refere a causa eficiente é dada devido ao fato de que o "poder laico foi dado ao género humano puro por Deus desde o começo do mundo, não sendo ainda o homem criado, ao passo que o poder eclesiástico foi dado por Deus depois de o homem criado" (AZPILCUETA, 2015, p. 96-97). A diferenciação é dada na causa material, "porque o poder laico foi dado diretamente para governar as coisas naturais, ao passo que o eclesiástico foi dado diretamente para reger as sobrenaturais" (AZPILCUETA, 2015, p. 97). Na causa final, "porque o fim do poder eclesiástico é uma condição sobrenatural neste mundo através da graça, e no outro mediante a glória eterna, ao

\footnotetext{
${ }^{15}$ Em uma de suas obras mais famosas, chamada "O Defensor da Paz", escrita entre 1318-1324, Marsílio de Pádua defende a ideia de que a autoridade civil, em todos os assuntos temporais, possui superioridade sobre a eclesiástica. Circunscrevendo, desta forma, a autoridade eclesiástica à esfera do sobrenatural afirmando, na referida obra, "a finalidade do sacerdócio como instrução e educação de homens, de acordo com a Lei Evangélica, no tocante ao que é necessário acreditar, fazer e evitar, de modo a obter a salvação eterna e livrar-se do seu contrário" (Liv. I, cap.VI, n. 8) retirando, de certa forma, do poder eclesiástico sua jurisdição no foro externo. Ver na edição em língua portuguesa: MARSíliO DE PÁDUA. O Defensor da Paz. Tradução e notas de José Antônio Camargo Rodrigues de Souza. Petrópolis: Vozes, 1997, p. 99.
}

NASCIMENTO, Marlo do. A filosofia política de Martín de Azpilcueta (1492-1586) e a questão da autoridade civil popular. Griot : Revista de Filosofia, Amargosa - BA, v.19, n.1, p.65-75, fevereiro, 2019. 
passo que o fim do poder laico é uma condição natural, a saber, uma vida boa e venturosa" (AZPILCUETA, 2015, p. 97). Por fim, nos diz, que a distinção é dada na causa formal, "porque o poder eclesiástico dirige principalmente segundo a lei sobrenatural, a saber, a regra evangélica, ao passo que o laico segundo a lei e razão naturais (AZPILCUETA, 2015, p. 97).

Acreditando, até aqui, ter demonstrado como Azpilcueta concebe sua definição, distinção e relação entre os poderes laico e eclesiástico é que podemos dar sequência neste trabalho no intuito de destacar o autor da Relectio C. Novit de Iudiciis como um dos defensores da ideia de que o povo é o titular detentor da autoridade civil popular, no século XVI.

\section{Sobre a autoridade civil popular}

Para que a defesa da ideia do povo como destinatário natural do poder civil em Azpilcueta possa ser afirmada, de maneira mais direta e clara, iniciaremos com a seguinte passagem, que acreditamos ser de profunda importância na defesa da questão, pois ela trata da origem, natureza e finalidade do poder político laico, que diz assim: "O poder laico se define corretamente como sendo o poder de modo natural dado imediatamente por Deus à comunidade dos mortais para que se governem nas coisas naturais, a fim de viverem bem e venturosamente de acordo com a razão natural" (AZPILCUETA, 2015, p. 95). Na sequência do texto o autor apresenta o conjunto de referências que de certa forma lhe ajudaram a fundamentar a sua posição. Com destaque para a autoridade bíblica, Aristóteles, Tomás de Aquino, Cícero entre outros. Cabe ainda ressaltar, conforme Jorge de Otaduy Guerín (1988, p. 317), que a elaboração doutrinal de Azpilcueta referente ao poder civil encontra com certeza seus fundamentos na filosofia escolástica medieval, porém seu pensamento constitui um avanço significativo sobre o conjunto de autores anteriores, que se expressa tanto no conteúdo das proposições quanto na forma de expressão.

O pensador espanhol ao dizer que o poder laico deriva de Deus de maneira natural está justamente se colocando na posição contrária a teoria contratualista moderna. Isso porque o poder que o povo possui não deriva da vontade humana, e sim, da vontade divina. Pelo fato da comunidade humana receber este poder, de maneira natural e imediata, de Deus retira qualquer possibilidade de pensar que o poder laico possa ter sido conferido ao sumo pontífice e nem mesmo à reis ou imperadores. Por isso, neste caso, o papa não possui autoridade de conferir poder a qualquer tipo de governo temporal. Ainda conforme Azpilcueta (2015, p. 97) a leis seculares são elaboradas e decorrem do poder laico e natural.

Como já visto, para Martín de Azpilcueta o poder é, sim, dado imediatamente de Deus à comunidade dos mortais para que se governem. Porém, para que esse poder no caso concreto resida em uma autoridade civil específica, ou seja, para que esse poder resida em alguma pessoa da comunidade deve haver a intervenção humana. Sendo assim, somente mediante essa intervenção que poderá existir uma autoridade política civil legítima em concreto. $\mathrm{O}$ autor da Relectio, ao proclamar a origem divina imediata do poder abstrato está apelando a uma instituição de direito

NASCIMENTO, Marlo do. A filosofia política de Martín de Azpilcueta (1492-1586) e a questão da autoridade civil popular. Griot : Revista de Filosofia, Amargosa - BA, v.19, n.1, p.65-75, fevereiro, 2019. 
natural ${ }^{16}$, isso porque sua justificação não se pauta na vontade dos homens, e sim, na ordenação divina e, portanto, no direito natural (TAPIA, 1997, p. 179).

Tendo presente o que já foi dito, Azpilcueta demonstra ter sido, enormemente influenciado pela filosofia escolástica, de cunho aristotélico-tomista, ao dizer que o fim natural do poder laico é viver bem e venturosamente. Ideia esta que de certa forma também indica que a finalidade do poder político da comunidade dos mortais é a busca do bem comum.

Ademais, em consonância com o pensamento de Jacques Almain ${ }^{17}$ destaca Azpilcueta que "o reino não é do rei, mas da comunidade, e o próprio poder régio, por direito natural, é da mesma comunidade, e não do rei, motivo pelo qual não pode a comunidade renunciar totalmente a ele" (Azpilcueta, 2015, p. 102-103). Dessa forma, deixa claro que o poder do reino pertence ao povo reunido em comunidade e assim fundamentando-se no jusnaturalismo escolástico está destacando que o poder civil, por direito natural, é de origem popular e é algo inerente e inalienável à comunidade.

\section{Considerações finais}

Tendo em mente, o que fora exposto até então, podemos apontar a obra Relectio Cap. Novit de Iudiciis, de Martín de Azpilcueta, como sendo uma grande referência para compreender o pensamento político escolástico e, porque não, o pensamento político fundado na filosofia medieval.

Para finalizar este trabalho é importante destacar que é possível defender a ideia de esta obra estudada é uma das essenciais para que se possa compreender a filosofia política medieval e, de maneira específica, o pensamento político da escolástica tardia.

Primeiro porque o Dr. Navarro consegue, a partir de sua vasta erudição, trazer para a discussão as principais fontes do pensamento político-jurídico de sua época e da tradição filosófica medieval. $\mathrm{O}$ que muito lhe favoreceu para posicionar-se com clareza sobre as questões propostas.

\footnotetext{
${ }^{16} \mathrm{O}$ direito natural é para Azpilcueta "el conjunto de normas naturales, obligatorias, indeterminadas, evidentes por sí mismas o por dedución de los primeiros princípios y conocidas espontaneamente por la razón Natural" (TAPIA, 1997, p.111).

17 Sobre Jacques Almain, temos que: O professor John Mair (1467/9 - 1550) durante sua longa carreira como docente na Universidade Paris teve vários e reconhecidos alunos entre eles podemos citar: Pierre Crockaert (ilustre professor de Francisco de Vitória em Paris), o humanista George Buchanan e os reformadores Jean Calvin e John Knox. Porém, entre os maiores em mais reconhecidos dos seus alunos, contemporaneamente, a julgar pelo seu apelido "Esplendor Academiae" foi Jacques Almain (1480-1515). Jacques Almain, apesar de sua morte prematura, escrevera uma vasta obra tratando de vários temas, entre eles: lógica e filosofia natural, realizou um intenso comentário sobre os dois últimos livros das sentenças de Pedro Lombardo e ainda produziu um amplo trabalho sobre ética. Em ambas obras: Moralia (tendo cinco edições entre os anos 1510 à 1525) e em uma Expositio de Guillherme de Ockam Octo questiones de potestate pape (McGRADE, 1997, p. 13). Azpilcueta é claramente influenciado por pensadores nominalistas como Gabriel Biel, John Mair e Jacques Almain. Podemos dizer que o Dr. Navarro se considera um sucessor dessa tradição da filosofia política que se destaca pela defesa da soberania popular. Importante ainda salienta que Azpilcueta na Relectio in Cap. Novit de Iudiciis demonstra ser influenciado, de fato, por Jacques Almain ao citá-lo, somente na Anotação III vinte e uma vez frente as vinte seis vezes que cita Tomás de Aquino (TAPIA, 1997, p. 116).
}

NASCIMENTO, Marlo do. A filosofia política de Martín de Azpilcueta (1492-1586) e a questão da autoridade civil popular. Griot : Revista de Filosofia, Amargosa - BA, v.19, n.1, p.65-75, fevereiro, 2019. 
No segundo ponto, Azpilcueta ao apresentar como ocorre a distinção e a relação entre os poderes eclesiástico e laico vem trazer um novo olhar para esta questão e ser de certa forma renovador da tradição política-jurídica que lhe precede.

Num terceiro aspecto temos que, sua teoria do poder indireto vem ser uma forma de manifestar o limite do poder eclesiástico sobre assuntos de ordem temporal. Assim sendo, o sumo pontífice tem poder de manifestar-se diante de assuntos temporais se, e somente se, sua intervenção tiver vistas a um fim que seja de caráter sobrenatural.

Por fim, é possível destacar que no pensamento político de Martín de Azpilcueta, a defesa da tese de que o poder originário laico tem no povo o seu legítimo depositário é apresentada de maneira clara e objetiva, principalmente, quando ele aborda a questão da origem e natureza do poder laico. Por sua vez, ao dizer que o poder laico é dado por Deus a comunidade de maneira imediata e natural está afirmando de maneira categórica que o poder supremo laico tem sua origem no povo, disso decorre a igualdade original primária de todos os homens na vida pública, e que este poder tem como finalidade a vida feliz e venturosa.

Tendo isso presente, pode-se afirmar que Martín de Azpilcueta, ao defender que todos os homens são iguais por serem detentores desse poder civil originário, que se realiza de fato na comunidade, está ao mesmo tempo, conforme Calafate $(2015, \mathrm{p}$. 211), alegando que todos os povos do orbe são possuidores naturais da soberania política, do direito de domínio de jurisdição e de propriedade da terra. Esta consideração pode ser feita pelo fato de que o princípio da sociabilidade intrínseca entre os povos politicamente organizados encontra o seu fundamento no direito natural. Logo, o respeito que merecem as comunidades políticas espalhadas por todo o mundo não é derivado de sua fé, de seus costumes e nem de sua localização geográfica terrestre, e sim, do poder civil intrínseco que o povo tem de se governar. Neste sentido, é que a Relectio in Cap. Novit de Iudiciis apresentada por Azpilcueta, em Coimbra, em meados do século XVI, acabou sendo uma obra de extrema relevância para a época, pois a questão que se colocava como pano de fundo para esta sua reflexão na Relectio era a da autoridade política dos povos originários do continente americano, este recém descoberto por parte dos ibéricos. 


\section{Referências}

ARISTOTLE. Categories. In: BARNES, Jonathan. The Complete Works of Aristotle. The Revised Oxford Translation. 2 vols. (Bollingen Series, 71: 2). 1984.

AZPILCUETA, Martín de. Relectio c. Novit de Iudiciis. In: CALAFATE, Pedro. A Escola Ibérica da Paz nas Universidades de Coimbra e Évora (Séculos XVI e XVII) (vol. II). Coimbra: Edições Almedina, p. 23-181, 2015.

CALAFATE, Pedro. O pensamento político de Martín de Azpilcueta: sobre o poder supremo. Filosofia Unisinos, v. 18, n. 3, p. 203-212, 2017.

CASTAÑEDA, E. El Dr. Navarro, Martín de Azpilcueta y la doctrina del poder indirecto. In: Archivo teológico granadino, n. 5, p. 63-94, 1942.

GUERÍN, Jorge Otaduy. La doctrina de Martín de Azpilcueta sobre la potestad civil y su influjo en la teoría del poder indirecto. In: El el IV centenario de la muerte de Martín de Azpilcueta. Gobierno de Navarra, Pamplona: EUNSA, p. 313-330, 1988.

INOCÊNCIO III. Novit Ille. In: CALAFATE, Pedro. A Escola Ibérica da Paz nas Universidades de Coimbra e Évora (Séculos XVI e XVII) (vol. II). Coimbra: Edições Almedina, p. 183-189, 2015.

LOYN, Henry R. Dicionário da Idade Média. Trad. Álvaro Cabral, 2.ed. Rio de Janeiro: Jorge Zahar, 1991.

MARSÍlio DE PÁDUA. O Defensor da Paz. Tradução e notas de José Antônio Camargo Rodrigues de Souza. Petrópolis: Vozes, 1997

McGRADE, Arthur Stephen. Jacques Almain. In: KRAYE, Jill (Ed.). Cambridge translations of Renaissance philosophical texts. Volume 2: Political Philosophy. Cambridge University Press, 1997.

STREFLING, Sérgio Ricardo. A filosofia política na Idade Média. Pelotas: NEPFIL online, 2016.

TAPIA, Ramón Martínez. Filosofía política y derecho en el pensamiento español del s. XVI: el canonista Martín de Azpilcueta. Granada: Colegio Notarial de Granada, 1997.

TOMÁS DE AQUINO. Suma Teológica. vol. IV. São Paulo: Edições Loyola, 2005.

Autor(a) para correspondência: Marlo do Nascimento, Universidade do Vale do Rio dos Sinos, Av. Unisinos, 950, Cristo Rei, 93022-750, São Leopoldo-RS, Brasil.marlo_kn@hotmail.com 